\title{
Artificial Intelligence and Human Society
}

\section{Inteligencia artificial y sociedad humana}

DOI: $10.46932 /$ sfjdv2n4-003

Received in: May 1st, 2021

Accepted in: Jun 30th, 2021

\author{
Dr. Alka Jain \\ Senior Research Fellow, ICSSR, New Delhi
}

\begin{abstract}
Artificial intelligence is the latest stage of technological revolutions, through which mankind is undergoing at present. We have crossed the four phases of first agricultural, second $18^{\text {th }}$ century industrialrevolution, third $20^{\text {th }}$ century industrial revolution and fourth 1970 's scientific revolution. We have entered in to fifth era of information technology revolution when

- Machines are talking to machines

- Machines are talking to humans and

- Machines have gained the power of reasoning.

Sophia robot is the latest example of such a revolution. Previous stages of technological revolutions have affected economic environment more than the social environment. Machines had brought changes in economic productivity and we have seen it very recently, but with the introduction of intelligent machines, we are bound to see drastic changes in the human society itself. The fact is reflected in the citizenship for the robot 'Sophia'. We see that machines have started becoming humans. The paper proposes to study the effect of these changes on human psychology and then as later effect on the society and the units of the society of the country. Psychological changes in the mankind have hardly been addressed by previous scholars. Path of research will be

Artificial intelligence $\longrightarrow$ Impact on human psychology $\longrightarrow \quad$ Impact on Indian society

Primary and secondary data will be collected to study these impacts. Survey tool will be used for data collection. The analysis and interpretation of the data will give us research outcome which can prove helpful in decision making for the future development of artificial intelligence techniques and their acceptance in the society. Such researches can surely contribute in giving correct direction to innovationsin science and their adaptation in the society.
\end{abstract}

Keywords: Artificial intelligence, Indian society, social system, robots, intelligent machines, mankind.

\section{INTRODUCTION}

The term 'Artificial' means whatever is not provided by the nature or is created by man. Intelligence is another word for wisdom, so when we say artificial intelligence, we talk about man made wisdom. Wisdom is the only power in human beings that differentiates him from other animals in the world. The computer technology has brought in the concept of artificial intelligence. It is used for voice recognition, small technical or household work etc. This technology is producing machines with wisdom/intelligence which can take decisions on their own or can perform the way a human accomplishes 
a task. Though it is in infancy stage, there are expectations of highly developed machines which will work with efficiency better than humans. ${ }^{1}$

Google is one of the top organizations which are putting in best efforts to bring the benefits of Ai to everyone. In fact the paper would be incomplete if we do not take the name of the master AI organization-Google. The company is involved in research and development that can be applied to new areas of work. It is also trying to develop various tools which are accessible for everyone. Samsung, Mi, Whirlpool and many other companies are also there in the market which are developing their own $\mathrm{AI} / \mathrm{machine}$ learning tools and using them for marketing purposes. The main motto of these companies is to help people everywhere solve problems by using innovative methods. But at the same time they have a challenge of developing artificial intelligence responsibly for the benefit of people.Artificial intelligence is also called knowledge based development and it is the responsibility of these developers that they should not concentrate on the profit making aspect of this technology but also should think of making contributions towards the uplift of society.

\section{OBJECTIVE OF THE STUDY}

1. To analyze the perception of artificial intelligence consumers on its

- Development

- Usage

- Challenges

faced in this transition phase.

2. To assess the acceptance of usage of robots in particular areas of services or particular posts.

\section{RESEARCH QUESTION}

How do consumers perceive the impact of artificial intelligence on the Indian society and Indian economy?

\section{HYPOTHESIS}

1. Services provided by robots are accepted by the consumers/customers of AI services.

2. Artificial intelligence will help in the growth and development of the Indian economy.

\section{RELATED QUESTIONS}

- Is the purpose of artificial intelligence human convenience?

- Is artificial intelligence used in the following services/activities? 
- In buying medicines

- Providing travel instructions

- Providing entertainment

- Replacing human labour

- Providing news and personally relevant information

- Performing mechanics, such as fixing cars or other equipment

- Providing companionship to the elderly people

- Offering health care services

- Posting to social media accounts regularly

- Getting Financial/Investment advice

- Getting legal advise

- Cooking a meal

- Teaching etc.

- Do humans accept the services of robots in the following posts/ areas?

- Salesmanship

- In household work (maids and servants)

- Haircut

- Other beauty care services

- Ordinary medical services like massage etc.

- Teaching

- Receptionist

- Waiters

- Air hostess/steward

- Pilots/drivers

- Hero/Heroines in movies

- Prime minister/president of a country

- Surgeon for a family member's surgery

- Security person

- Police/fire service man

- Soldiers

- Baby sitters

- What are the views of consumers of artificial intelligence services on:

- Making the life of working women easy/less difficult 
- Making the organizations conflict free

- $\quad$ Easing the domestic labor for Indians

- What will be the status of Indian FMCG markets after entry of robots?

- What will be the employment pattern in the organizations of the country?

- Do we see an opportunity of global coverage for Indian products with the help of AI?

- Should the technology of artificial intelligence be promoted for economic benefits?

- Can these robots help in increasing the GDP of the country?

- What if artificial intelligence used for criminal offences?

\section{RESEARCH METHODOLOGY}

The research is empirical by nature. The research design is a blend of quantitative as well as qualitative. In the phase of data interpretation and Analysis, qualitative data has taken the form of descriptions based on language or images, while quantitative data has taken the form of numbers.

The survey tool has been used for data collection with a sample size of 90 . Primary data has been collected from educated youth of various states of the country. Secondary data has been collected from the previous scholarly literature work and magazines, newspapers etc.

\section{DEMOGRAPHIC PROFILE OF RESPONDENTS}

- $73.3 \%$ respondents are in the age group of 18-25 years and 26.6\% respondent are in the age group of 26-50 years.

- $45 \%$ out of these respondents were female while $55 \%$ were males.

- $4.4 \%$ respondents were XII passed, all other respondents were either graduates, postgraduates or $\mathrm{Ph}$ D degree holders.

- $69 \%$ respondents are students while $29 \%$ are employees/professionals or self employees. $2 \%$ are not working anywhere.

- Geographical location of respondents:

- Major no. of respondents were from Delhi , Jaipur and Bangalore. Few responses were received from the cities- Chandigarh, Calicut, Hyderabad, Jabalpur,Pune and Thrissur. The following diagram shows the geographic profile of respondents for the study: 
Diagram 1: Geographical Coverage of the Study

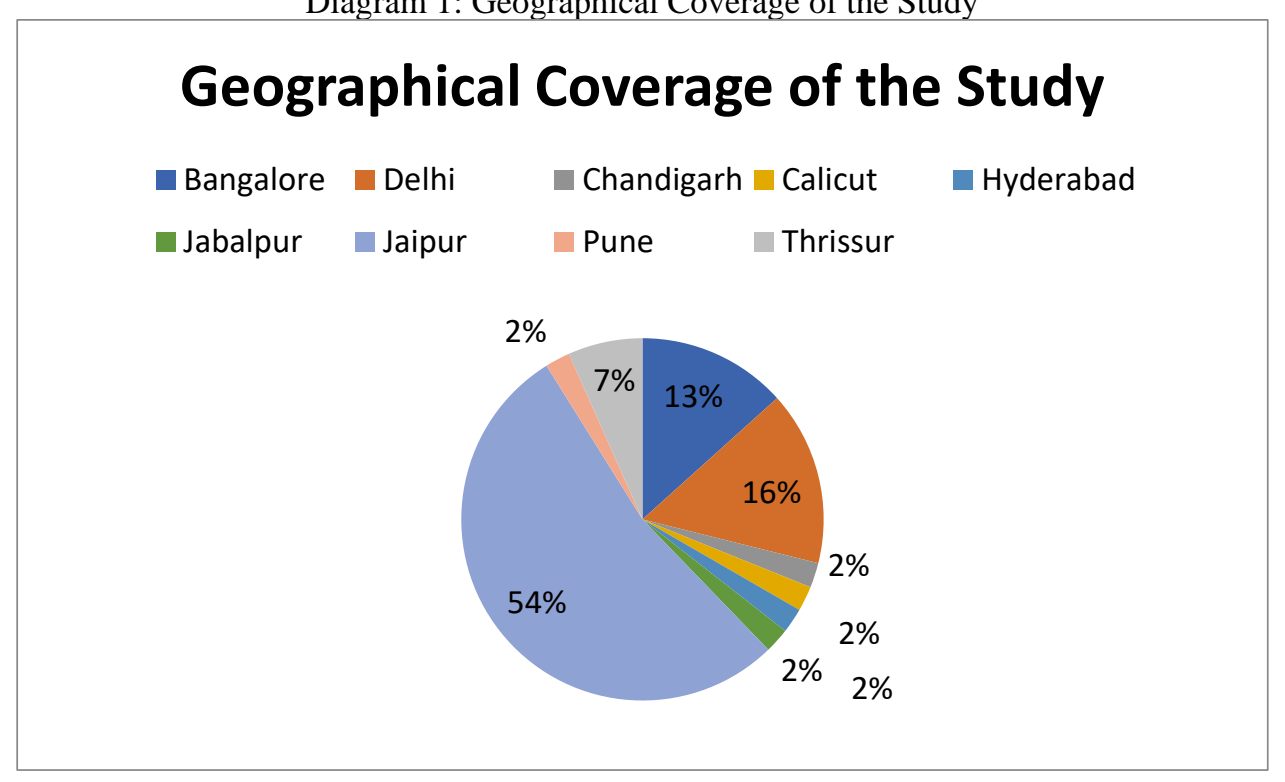

The data collected was analyzed and interpreted by the researcher which led to certain findings which further lead to suggestions and recommendations to the decision makers of the industry and the economy.

\section{LITERATURE REVIEW}

- Allan M. Jordan shares the thrill of use of artificial intelligence in drug design. He quotes Derek Lowe that Ai will not be the end of medicinal chemist, but it will be the end of medicinal chemists who do not use AI. Allan agrees to Mark and believes that this will become true, if not today, tomorrow. He suggests the readers to learn a lesson from the rise, fall and rise again of computational chemistry. He also recommends the use of tacit knowledge to unforeseen problems in a meaningful way for possible successful solutions. ${ }^{2}$

- Ajay Agarwal, Joshua Gans and Avi Goldfarb are of the opinion that artificial intelligence is an outcome of technology revolution in the $21^{\text {st }}$ era. Nothing else in the technology has affected the lives of human beings till now the way artificial intelligence has affected. The authors have studied the impact of artificial intelligence in the area of productivity, innovation, market power and employment. They have also studied potential economic consequences of machine learning. ${ }^{3}$

- Bostormlooks at some of the ethical issues related to creation of artificial intelligence at all levels. These are not merely machine challenges but are being criticized because of their ability to aurpasss human intelligence. Chess is one example where the algorithms have beaten human intelligence, but this is not the only field. Artificial intelligence if enters other intellectual fields, the future may be dangerous for us.Moral status of these intelligent machines is also discussed. ${ }^{4}$ 
- Bolton, Charlyne et. Al have reviewed the available literature on 'The Power of Human-Machine Collaboration: Artificial Intelligence, Business Automation and the Smart Economy'. The review talks about a smart economy as an outcome of this smart technology. According to them this smart economy will grow by $2035 \%$ after adoption of artificial intelligence by companies. They also analyze the job creation by AI and find a huge scope of opportunities lying ahead for international companies. ${ }^{5}$

- Bryn Jolfsson, Eric e Mcafee, Andrew -The MIT professors familiarize the readers with the idea of exponential growth. He talks about language learning of computers which is not learnt through learning to speak but by recognizing patterns based on everything that is written in a language so far. They also argue about the speed and ease both together while working with these second age machines. He touches the consumer reaction to these higher quality product and service offerings by the machines. ${ }^{6}$

- Goyal Jayanti in her paper 'Artificial Intelligence: A New Tool for Managing Stress' advocates the view that $\mathrm{AI}$ has started affecting our lives. She attempts to find the techniques of stress management through AI. She discusses various smart phone apps like Headspace and Calm which consists of libraries of different meditation, structured programs and push reminders.AI has improved the outcome of sensors and reflecting reactions. She concludes that stress managing technology to integrate effortlessly into the wide variety of lifestyles. ${ }^{7}$

- Jerry Kaplan, the artificial intelligence expert in his book 'Artificial Intelligence: What Everybody Wants to Know' discusses systems capable of independent reasoning. He raises a very genuine question, "For whom are they working?" He covers the issues related to limits the society should place on the spread of artificial intelligence. He also raises the question," Can a machine be held responsible for the decisions taken by it?"Answers to such serious questions is what mankind should look for. In case of an accident from a driverless car, who is supposed to take the responsibility. ${ }^{8}$

- J Mark Munoz and Al Naqvi have authored a book titled 'Business Strategy in the Artificial Intelligence Economy'. According to them, artificial intelligence has affected the economy and lifestyle worldwide. Hence the businesses have to redesign their strategies and policies which may lead to entirely new business management systems. The authors have also visualized the emergence of a new cognitive era. They also foresee the rareness of academic and business research on the topic. ${ }^{9}$

- Luke Dormehl in his book 'Thinking Machines', highlights that in 2016 the terms 'artificial intelligence' celebrated its $60^{\text {th }}$ anniversary. While discussing the evolution of AI, he shows his worry on all knowledge being converted into and treated as mere data. This data does not need human brains for itself to be stored, but can be easily stored on a micro chip which occupies no space, needs no 
feeding etc. He also uses the term smart machines and is afraid of the day when these machines go wrong. His worry about the future can be heard in the book. ${ }^{10}$

- Margarate A. Boden assesses creativity as the basic tool of intelligence. She emphasizes that even technologically oriented artificial intelligence cannot ignore creativity. She discusses three computer models of creativity and suggests that the exploratory type of model is most successful which is the basis of artificial intelligence. ${ }^{11}$

- Martin Ford's book 'Rise of the Robots' echoes the worries of jobless future. His statement , "Artificial intelligence is already well on its way to making 'good jobs' obsolete" tells that more training and education are no more a successful tool in the future for decent jobs. Evaporation of jobs is the only issue that has been described throughout the book. Many readers have shown their distress after completing the book. This tells us how fearful the future can be. ${ }^{12}$

- McKinsey Global Institute has prepared a report on artificial intelligence in September, 2018 . The report explains the potential of artificial intelligence in incrementally adding on to the global economic output. Artificial intelligence is to be treated as different from general purpose technologies. The report is based on simulation model and works on five elements of AI: Computer vision, natural languages,virtual assistance, robotic process automation and advanced machine learning. The technology has the capacity of affecting several factors from various industries in significant areas like workers, companies and economies, significant disruptions can be seen. ${ }^{13}$

- Ming Hui Huang lists the services provided by artificial intelligence - homes, healthcare, hotels and restaurants. He specifically mentions virtual bots which have turned customer service into self service. HE also mentions Chaudhary and Javelosan when he discusses the terms 'portfolio robots' (replaced by big data AI applications) and 'social robots' who greet customers in customer-facing services. Huang explains four types of intelligences in his paper- mechanical, analytical, intuitive and empathetic. He further gives examples of these intelligences used in business Self service technologies and service robots are mechanical intelligence, IBM's chess player is analytical intelligence, Google's DeepMindAlphaGo is intuitive while humanoid robot Sophia is an example of empathetic intelligence. He also developes a theory for understanding the nature of service work and how/why AI can substitute for or ultimately replace humans in each type of task/jobs.He names it the Theory of AI Job replacement which provides a road map about how AI advances to take over tasks. ${ }^{14}$

- Raju G. et. al provide insight for managers, marketers, e marketers and website administrators for their website agility, attractiveness and resilence They opine that usability of the website will influence the WOM intentions, making the website more useful for the consumers. ${ }^{15}$ 
- Tiruveedula et.al have worked on real world systems based on artificial intelligence.They discuss examples of 'Intelligence Distribution Agent (IDA) for the U.S. Navy, systems that trade stocks and commodities without human intervention, banking softwares, search engines and intelligent robots. They conclude that this automation can also be used in manual business decisions. They also foresee a hope of better alternatives in rule based processing, with the help of artificial intelligence.AI can also assist in selecting the best resource for a particular task based on the availability, reliability etc. ${ }^{16}$

- Yunhe Pan starts his paper 'Heading toward Artificial Intelligence 2.0' with 60 years history of evolution of AI. He discusses the reasons behind failure of AI2.0, the main reason found out is 'incompatibility with variations in the information environment'. During the discussion on significant influence of AI 2.0 on human development, he suggests the idea of cooperation between think tanks and international scientists for rigorous research in this field. ${ }^{17}$

\section{RESEARCH GAP}

The literature available till today (as read by the author) discusses technological and social impacts of artificial intelligence, when relationship between human beings and machines is referred to. The previous scholars talk about future developments in various fields and focus on the research activities. A few social workers/scholars have touched the area of human existence and stress generated from various problems like loss of jobs or human being surpassed by machines. One scholar Ming Hui Huang has talked about the services provided by AI or robots. But his approach is purely theoretical as he has developed a theory of AI job replacement. He hopes for a win-win situation between men and machines but does not provide us with a clear path. The author of this research paper proposes to touch the heart of human beings when facing this competition between humans and AI instead of their mind or brain. For example if you ask someone, "Would you recommend a robot surgeon in the healthcare field, the probable answer would be 'yes'. This is what mind speaks, but the moment you reframe the question and ask," Whom would you prefer between a robot surgeon and a human surgeon for a surgery of your ward/family member?" The question hits the heart of the respondent and we expect a slightly varied answer inclining towards 'No'. Such variations have been analyzed with the help of data collected. Another such example is :

- 'household work' and cooking a meal.

- 'General beauty care services' and a 'haircut' etc.

These actual feelings have been analyzed to reach an outcome whether the technology of artificial intelligence be promoted or not. 
Martin Ford has touched the economic issue - threat of jobless future, but sticks to social impact of this threat, while the proposed study aims to analyze the economic effects.

\section{DATA ANALYSIS AND INTERPRETATION}

\section{- Level of comfort with artificial intelligence based devices.}

A direct close ended question was asked from the respondents if they feel that ai is meant for convenience of the users. Such a question would give an idea of understanding about compatibility between the respondents and artificial intelligence. The respondents have been asked to rank their level of convenience with AI form 1 to 5 in the questionnaire. Ranking 1 to 3 stands for very high to average comfort level while 4 and 5 stand for relatively less comfort level of consumers. The data collected has been shown below in the Diagram 2:

Diagram 2: Level of Comfort with Artificial Intelligence

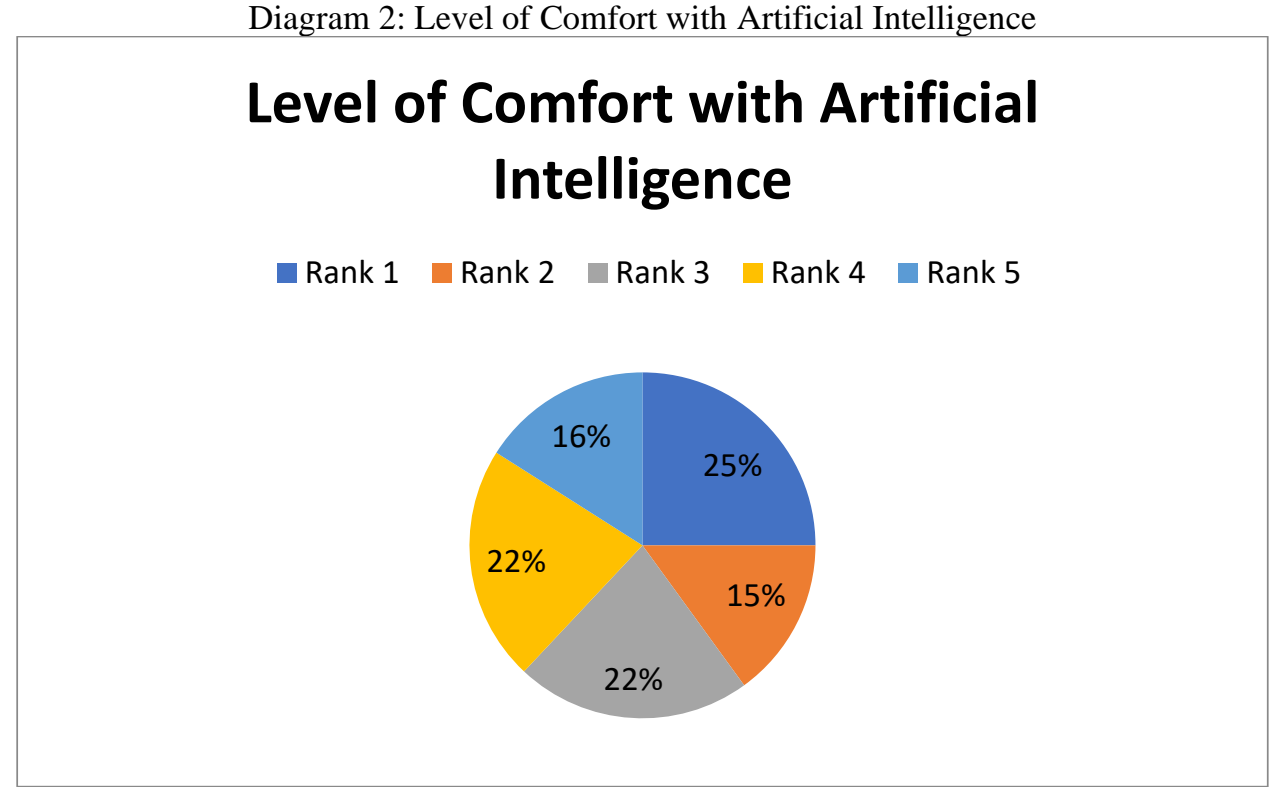

Analysis: The diagram depicts that $62 \%$ respondents find it convenient to use artificial intelligence for various tasks while 38\% respondents do not find it convenient to use artificial intelligence.

Finding: Since our age group is above 40 also so lack of knowledge on how to use ai for reading maps etc. can be possible reasons of such an attitude towards the use of ai.

- Usage of artificial intelligence in various activities performed by human beings: A question was framed for the respondents to check how much they use ai in their day to day activities like buying medicines, providing travel guidance, cooking meals, teaching, for entertaining themselves/others, replacing human labor, news and other relevant information, performing mechanics, healthcare services, getting legal and financial advices. 
- In buying medicines : $4.5 \%$ respondents always use ai for purchase of medicines, $33 \%$ use it very often and $14 \%$ use it often for purchase of medicines whenever they need it. $22 \%$ respondents use ai for the purchase of medicines seldom. $26.5 \%$ respondents have never used AI for purchase of medicines. The diagram below displays the data:

Diagram 3: Use of Artificial Intelligence in Buying Medicines

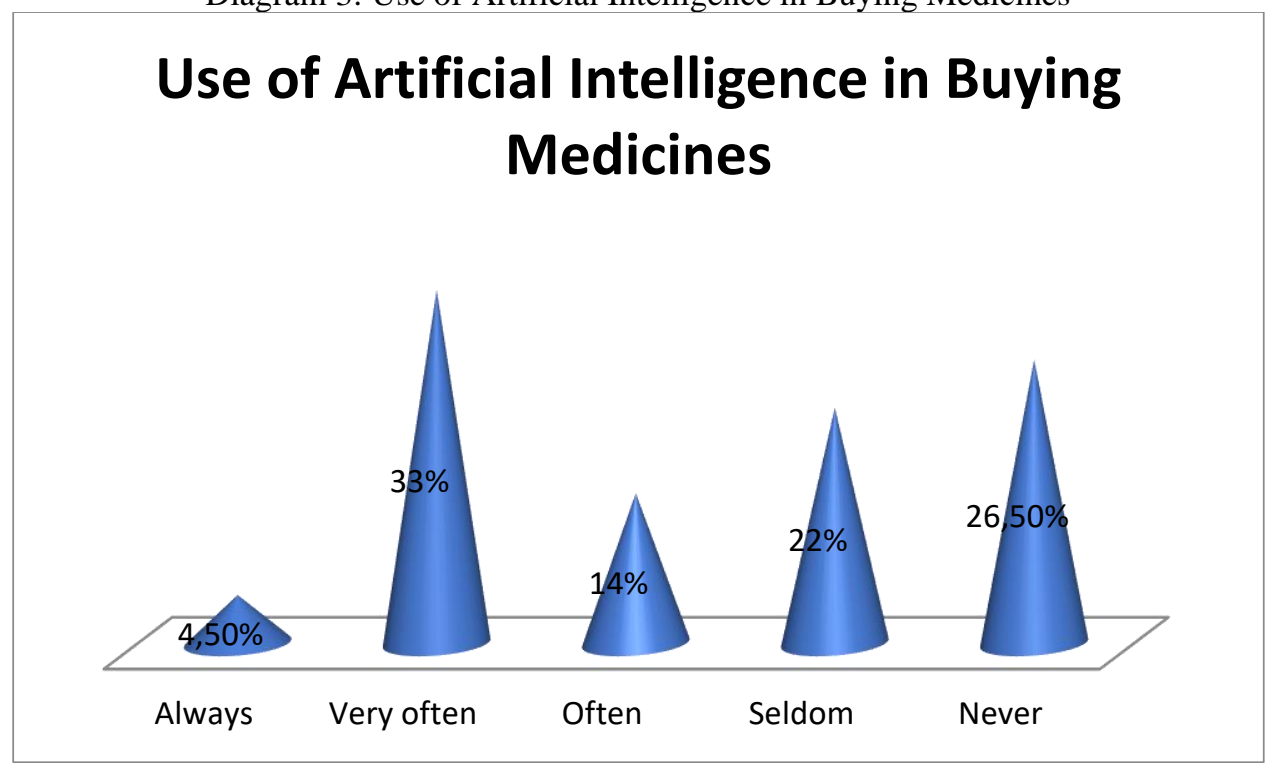

- Providing travel directions: For travel directions, 47\% use aI all the time while $28 \%$ and $15.50 \%$ use it 'very often' and 'often' respectively. Only $2 \%$ have never used AI for travel directions and $4.5 \%$ have seldom used 0it.

Diagram 4: Use of Artificial Intelligence in Providing Travel Directions

\section{Use of Artificial Intelligence in Providing Travel Directions}

- Série1

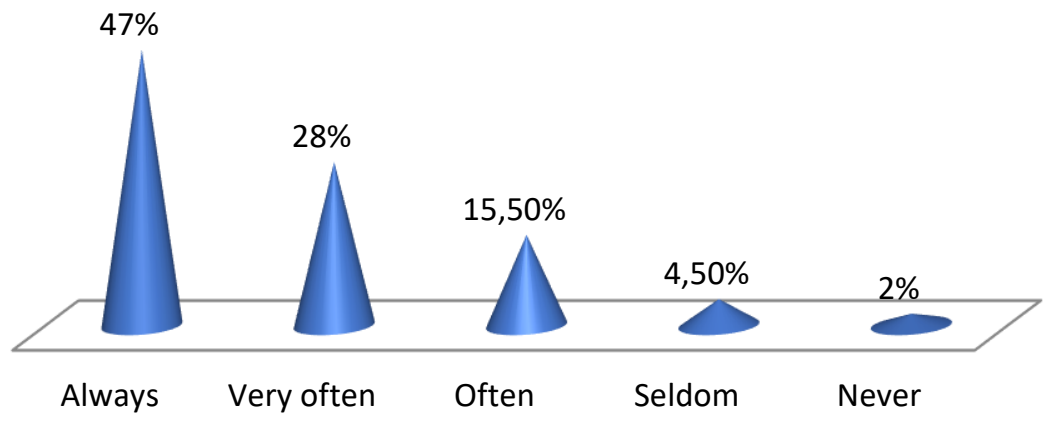


- Use of artificial intelligence in providing entertainment: For the purpose of entertainment there was nobody who has never used AI, $6 \%$ use it seldom. $34 \%$ of the respondents always use it for entertainment needs, while $43 \%$ use it very often, $17 \%$ use ai often to entertain themselves/others.

Diagram 5: Use of Artificial Intelligence in entertaining yourself/others

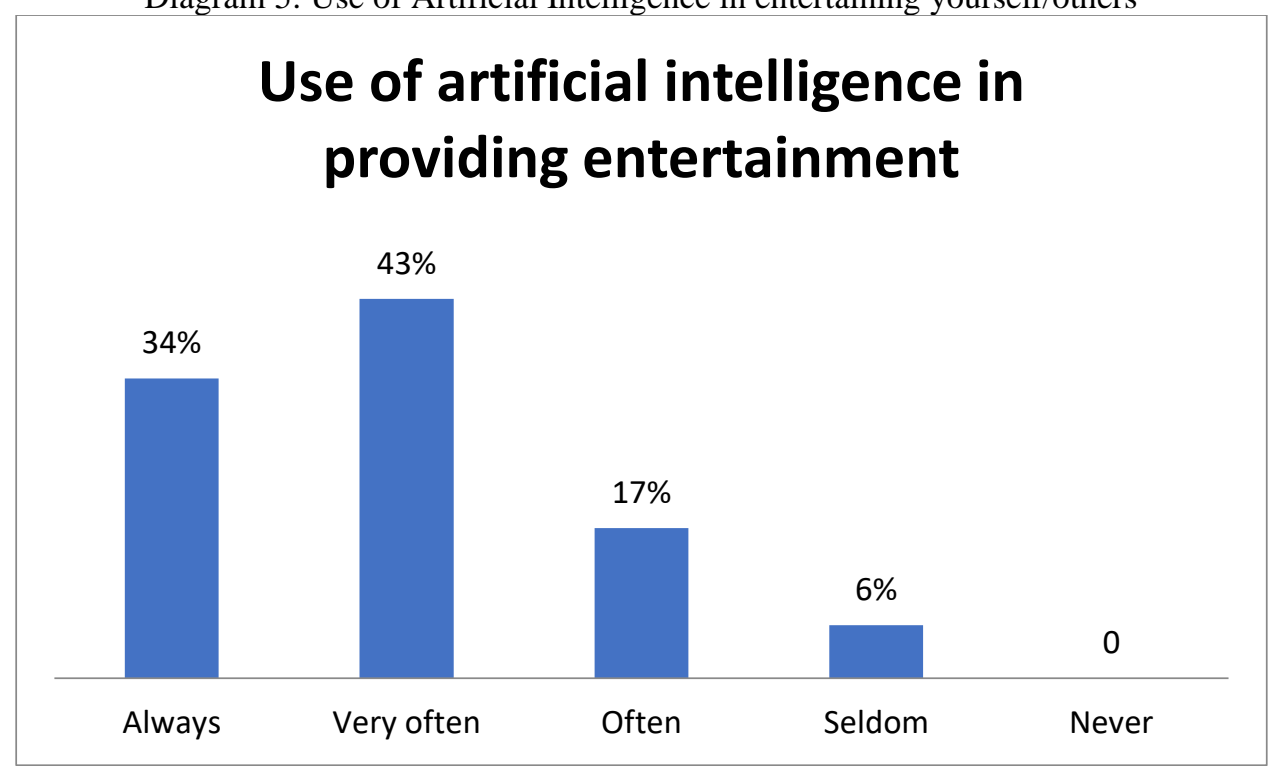

- Use of Artificial Intelligence in providing personally relevant news and information: $13.5 \%$ respondents are not dependent on AI for news or personally relevant information. $20 \%$, $31 \%$ and $35.5 \%$ respondents can be said to be dependent on AI for news and other information as they use it always, very often or often respectively as per the percentage.

Diagram 6: Use of Artificial Intelligence in Providing News and Information

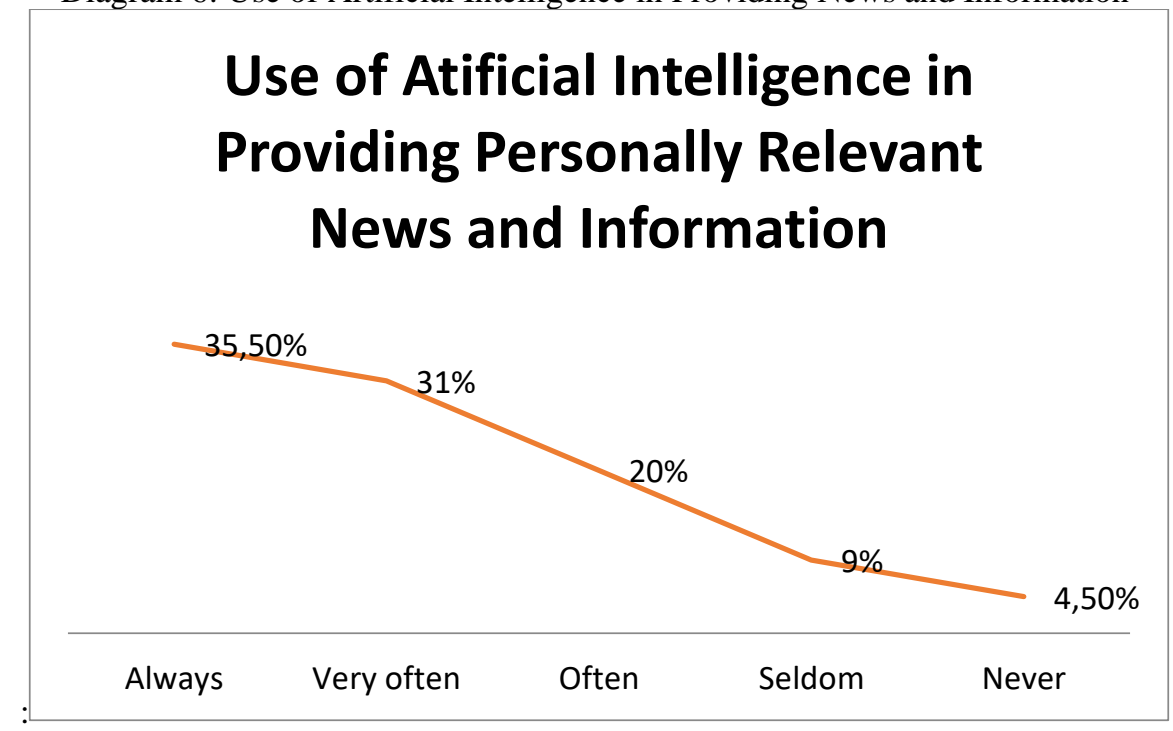


- Use of Artificial Intelligence in performing mechanics: When a question was asked about reliability of $\mathrm{AI}$ in performing mechanics like fixing cars or other equipment then $29 \%$ respondents revealed that they have never used Ai for performing mechanics, $13.3 \%$ had seldom used.11 and $20 \%$ of the respondents used AI always and very often respectively.

Diagram 7: Use of Artificial Intelligence in Performing Mechanics

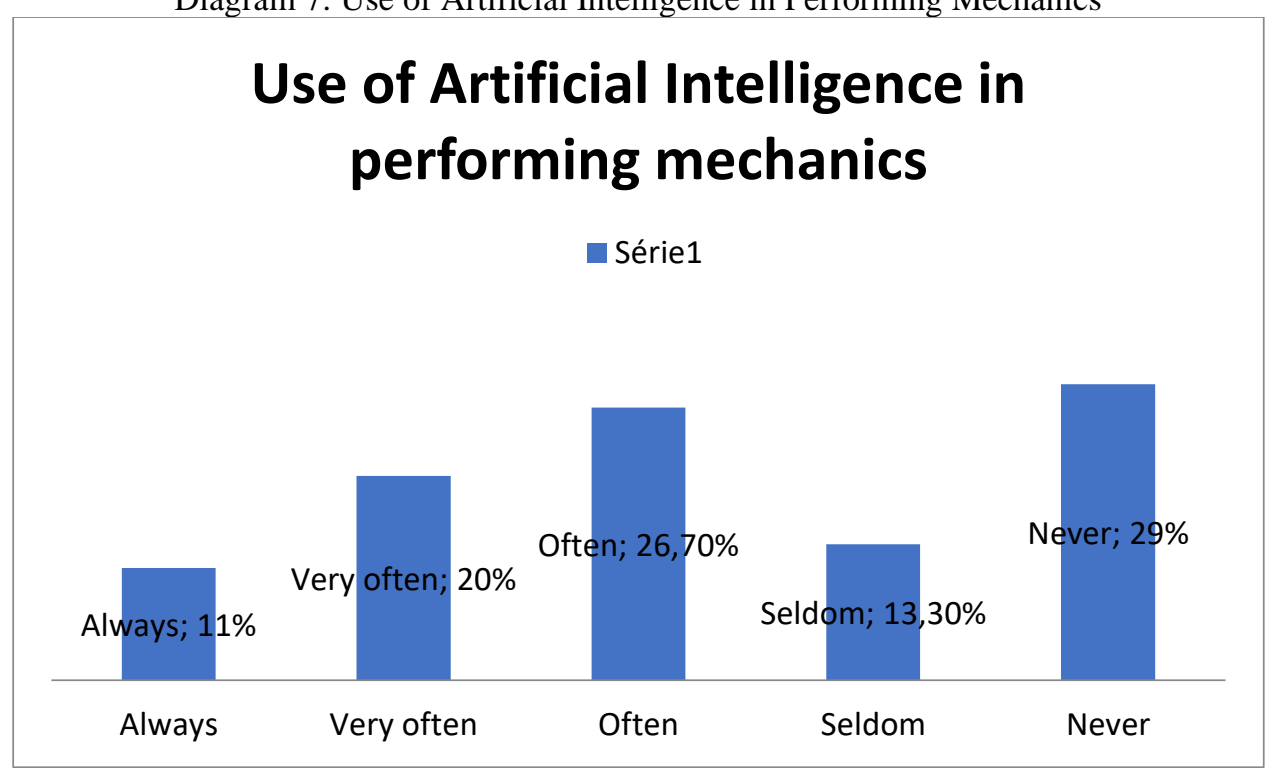

- Use of Artificial Intelligence in providing companionship to the elderly people of the society: $4.5 \%$ respondents use AI always when they need someone/something to keep the elderly people of the society accompanied. $40 \%$ respondents never or seldom use it. $31 \%$ and $24.5 \%$ respondents are in a habit of using AI for the purpose of giving some company to the elderly people of the family/society.

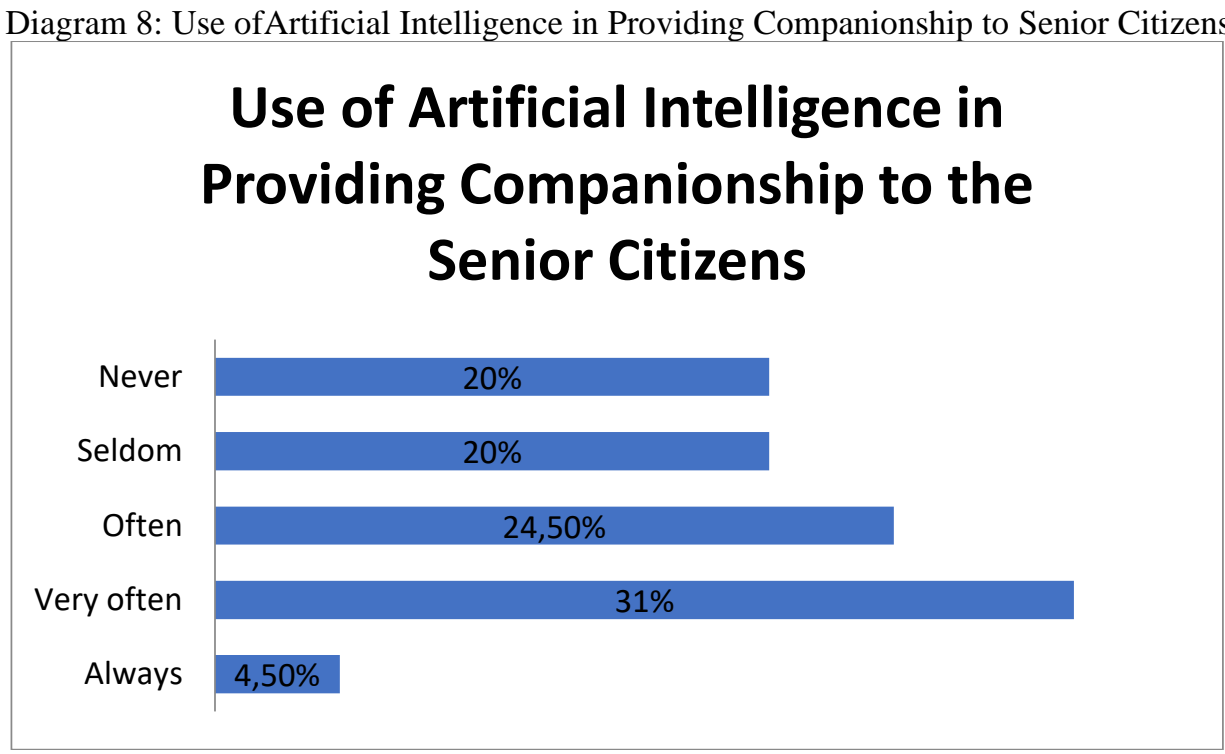


- Use of Artificial Intelligence in Offering Health Advice: 9\% respondents always use AI whenever they arein need of health or healthcare advice while $14 \%$ have never used it. $27 \%$ and $33 \%(60 \%)$ use it very often or often, $17 \%$ use it seldom.

Diagram 9: Use of Artificial Intelligence in Offering Health Advice

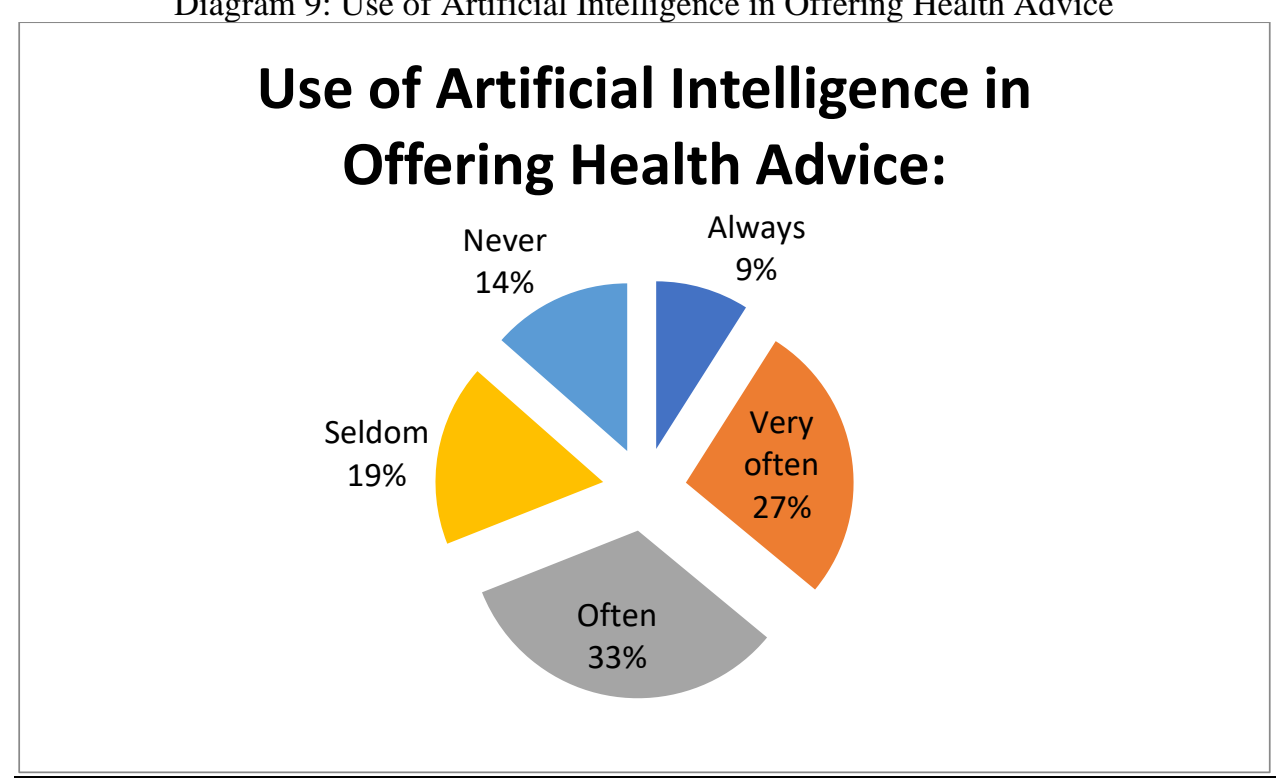

- Use of Artificial Intelligence in posting to social media accounts regularly: 29\% respondents use $\mathrm{AI}$ in posting to social media accounts regularly, $38 \%$ use it very often, for $18 \%$ the use is often while for $9 \%$ it is seldom. $6 \%$ respondents have never used it for the purpose.

Diagram 10: Use of Artificial Intelligence in Posting to Social Media Accounts Regularly

\section{Use of Artificial Intelligence in posting to social media accounts regularly}

$38 \%$

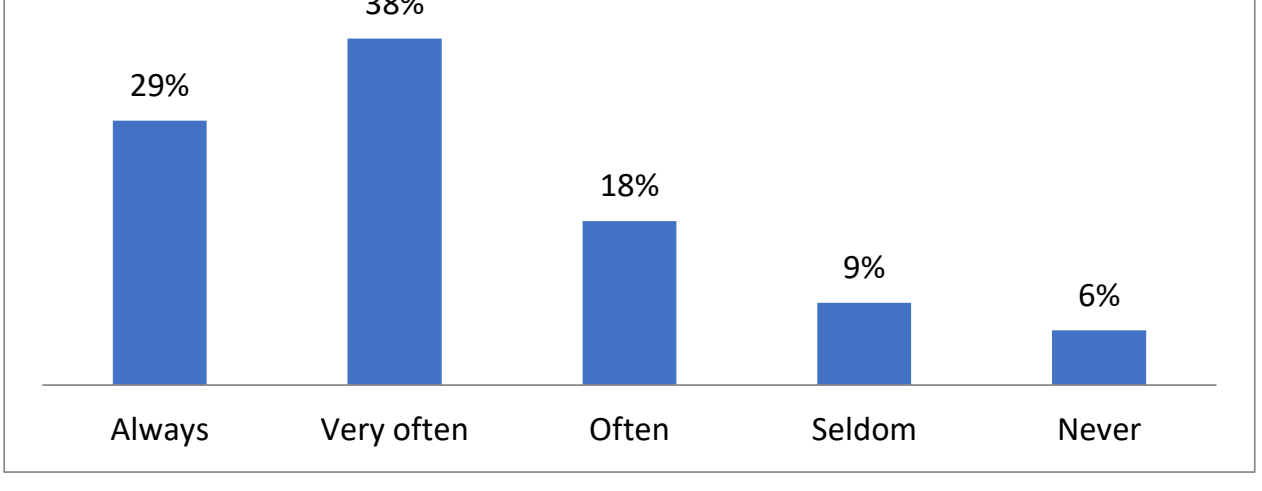


- Use of artificial intelligence in getting financial/investment advice: $20 \%$ respondents always use AI when they need financial/investment advice. $31 \%$ and $25 \%$ use it very often and often.8.5\% seldom use AI in such advices while $15.5 \%$ have never used AI for such decision making purposes.

Diagram 11: Use of Artificial Intelligence in Getting Financial/Investment Advice

\section{Use of artificial intelligence in getting financial/investment advice}

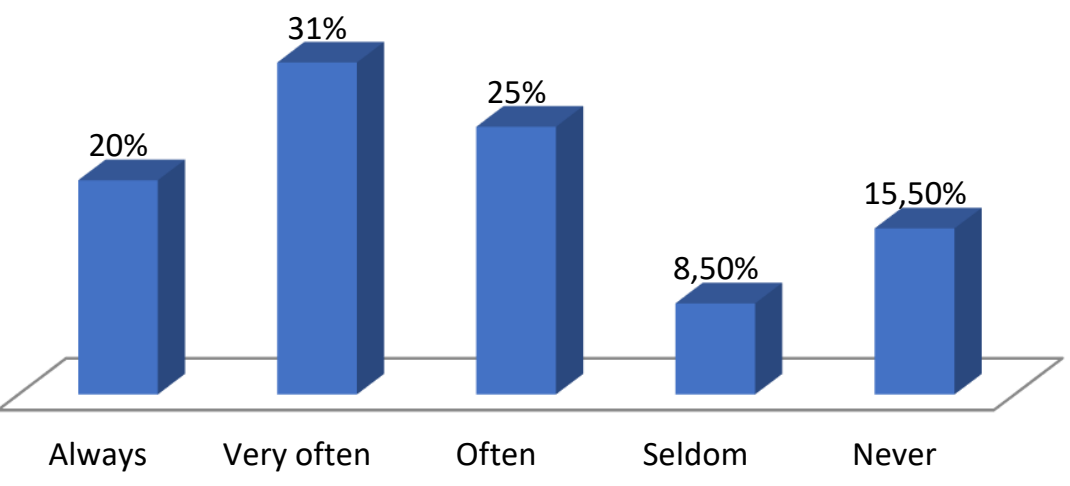

- Use of artificial intelligence in getting legal advice: 7\% always use on AI in getting legal advice. $55 \%$ respondents us it often or very often. $14 \%$ use it seldom and $24 \%$ have never used AI for legal advice.

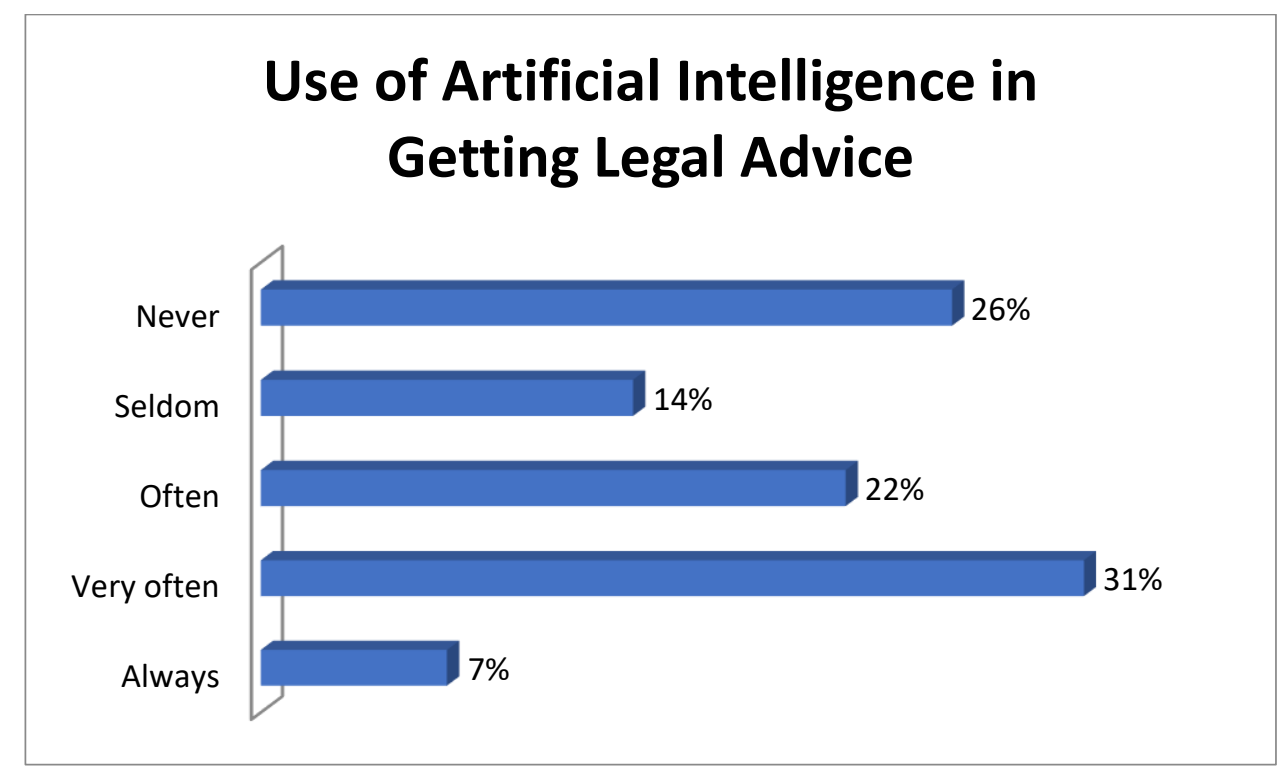


- Use of artificial intelligence in getting financial/investment advice:20\% respondents always use AI for getting financial/investment advice. For $(31 \%+25 \%) 56 \%$ it is very often or often to use AI for such decisions. 8.5\% respondents use AI seldom and $15.5 \%$ respondents never use it for financial and investment planning.

Diagram 12: Use of Artificial Intelligence in getting Financial/Investment Advice

\section{Use of artificial intelligence in getting financial/investment advice}

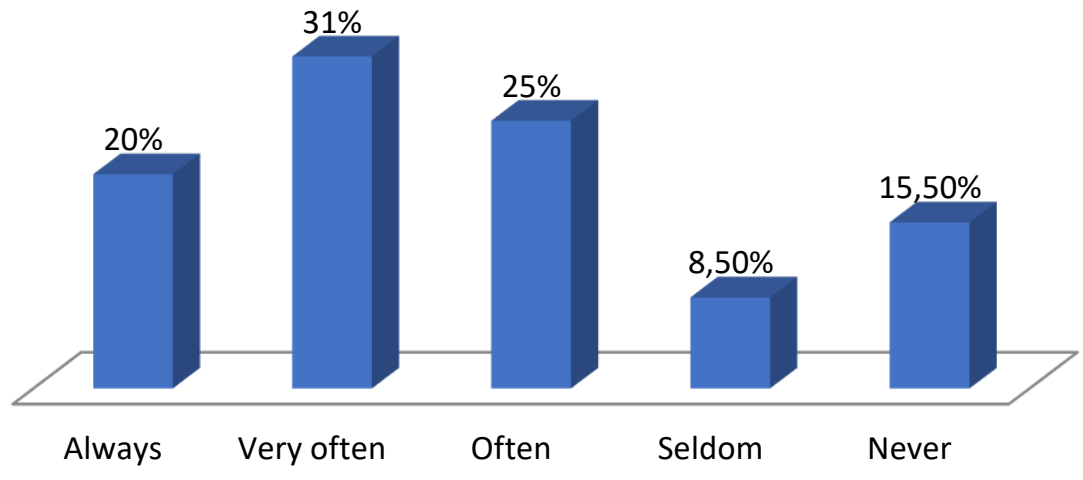

- Use of artificial intelligence in cooking a meal: While cooking meal, $6 \%$ respondents always use AI while $8 \%$ are there who never take help of AI.26\% use it often or very often and 5\% use it seldom.

Diagram 13: Use of Artificial Intelligence in Cooking a Meal

\section{Use of Artificial Intelligence in Cooking a Meal}

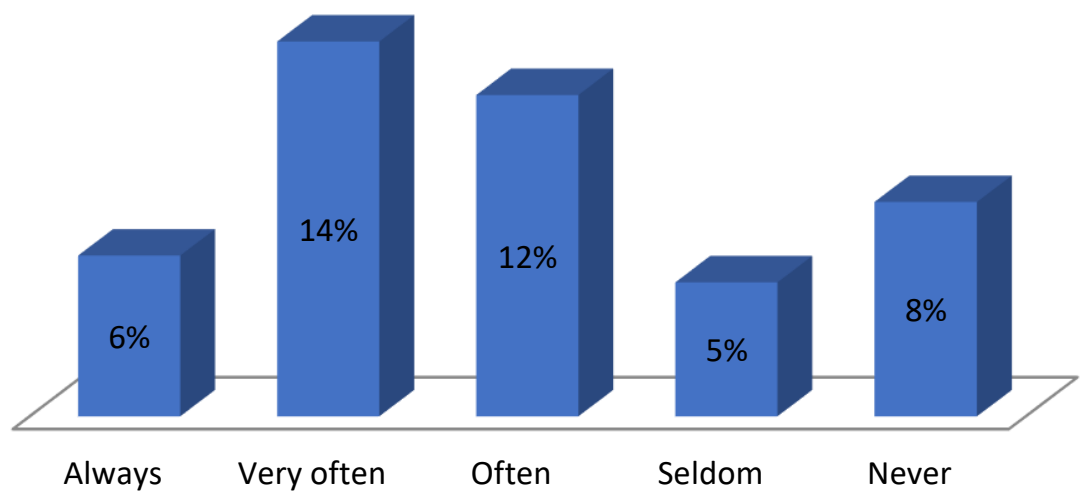


- Use of artificial intelligence in teaching: While teaching $11.1 \%$ respondents always use AI while $22.3 \%$ never use it, they trust on their own efficiency. $53.2 \%$ respondents use it often or very often while teaching. $13.3 \%$ use it seldom.

Diagram 14: Use of Artificial Intelligence in Teaching

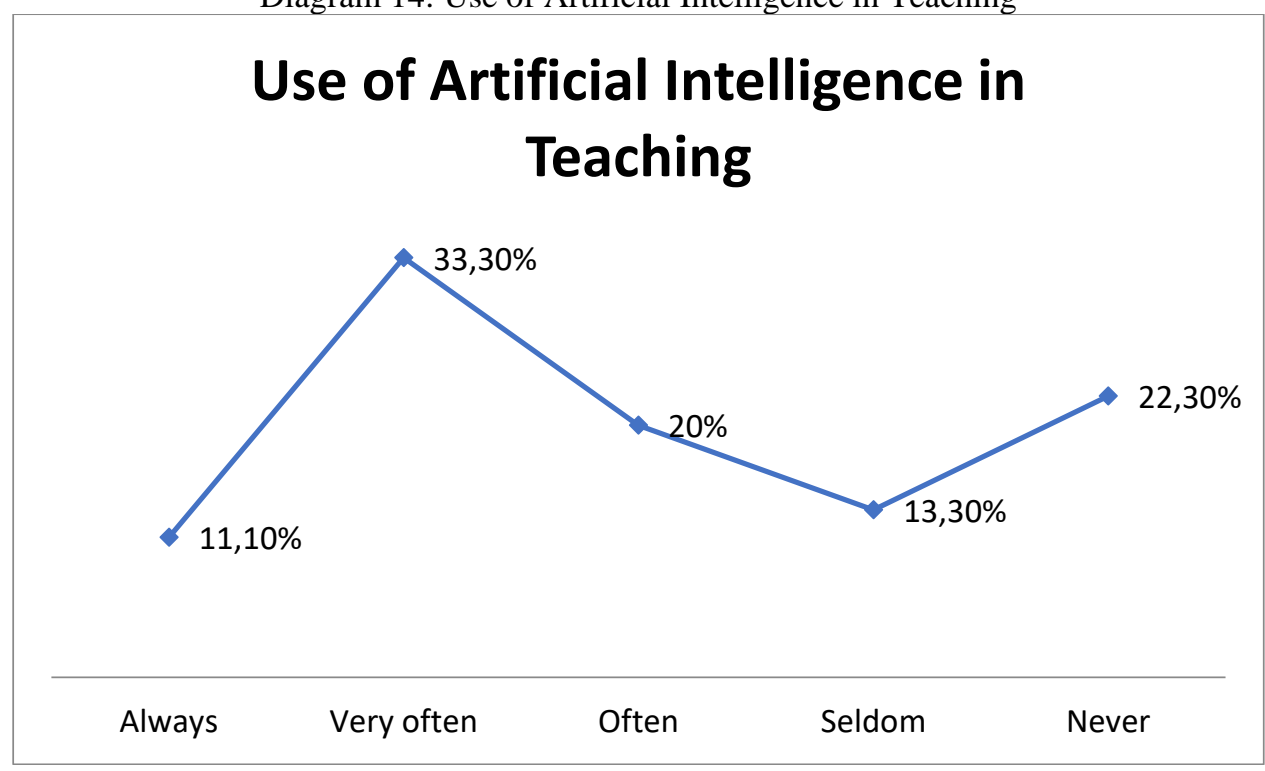

- Use of artificial intelligence in replacing/reducing manual labor

Overall use of artificial intelligence in reducing manual labor was assessed with the help of another question which was asked separately if ai helps them in reducing manual labor.

Diagram 15: Use of Artificial Intelligence in Reducing Manual Labor

\section{Use of artificial intelligence in reducing manual labor}

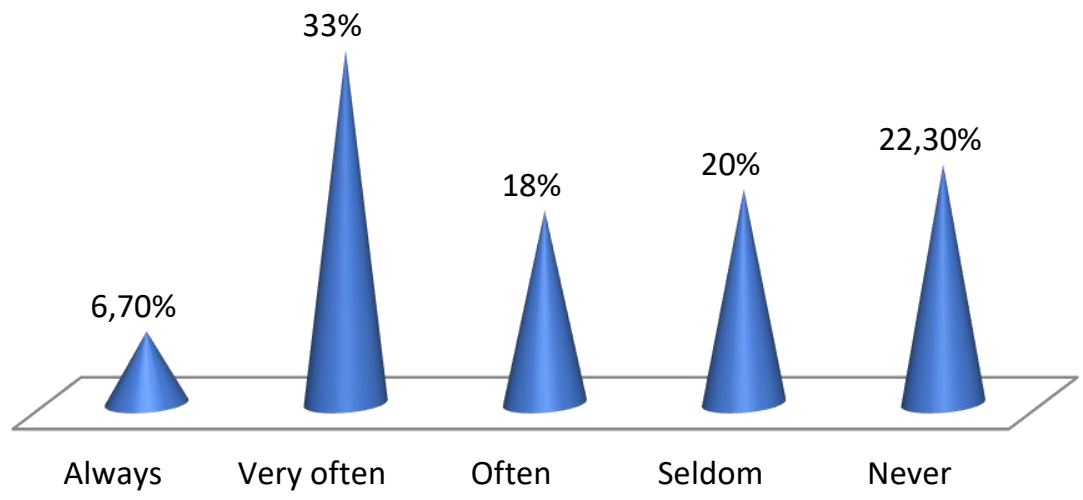




\section{RESPONDENTS' PERCEPTION ON USE OF ROBOTS IN VARIOUS HOUSEHOLD AND BUSINESS ACTIVITIES}

After analyzing the use of AI in various activities, perception of respondents about use of robots in these activities was studied, as robots are the future of AI and they look more like humans so can be accepted as helpers much easily. For the purpose of analysis the data has been shown in the table below:

Table 1: Respondents' perception on use of robots in various household and business activities

\begin{tabular}{|c|c|c|c|c|}
\hline S. No. & Factor studied & $\begin{array}{c}\text { Positive } \\
\text { perception } \\
\text { (Yes) } \\
\end{array}$ & $\begin{array}{c}\text { Negative } \\
\text { perception } \\
(\mathrm{No}) \\
\end{array}$ & Acceptability \\
\hline 1 & $\begin{array}{l}\text { Would you buy your products from a robot in the } \\
\text { market? }\end{array}$ & $69 \%$ & $31 \%$ & $\begin{array}{c}\text { Highly } \\
\text { acceptable }\end{array}$ \\
\hline 2 & Would you hire a robot for household work? & $58 \%$ & $42 \%$ & Acceptable \\
\hline 3 & Would you hire a robot for haircut? & $24 \%$ & $76 \%$ & $\begin{array}{c}\text { Never } \\
\text { acceptable }\end{array}$ \\
\hline 4 & Would you hire a robot for beauty care services? & $29 \%$ & $71 \%$ & $\begin{array}{c}\text { Not } \\
\text { acceptable } \\
\end{array}$ \\
\hline 5 & $\begin{array}{l}\text { Would you hire a robot for an ordinary medical service } \\
\text { like massage etc.? }\end{array}$ & $65 \%$ & $35 \%$ & $\begin{array}{c}\text { Highly } \\
\text { acceptable }\end{array}$ \\
\hline 6 & Would you accept robot as a teacher for your ward? & $38 \%$ & $62 \%$ & $\begin{array}{l}\text { Somehow } \\
\text { acceptable }\end{array}$ \\
\hline 7 & Would you accept robot as a receptionist/steward? & $69 \%$ & $31 \%$ & $\begin{array}{c}\text { Highly } \\
\text { acceptable }\end{array}$ \\
\hline 8 & Would you accept robots as waiters/waitresses? & $82 \%$ & $18 \%$ & $\begin{array}{c}\text { Highly } \\
\text { acceptable }\end{array}$ \\
\hline 9 & Would you accept robots as air hostesses? & $54 \%$ & $46 \%$ & Acceptable \\
\hline 10 & Would you accept robots as pilots/drivers? & $29 \%$ & $71 \%$ & $\begin{array}{c}\text { Not } \\
\text { acceptable }\end{array}$ \\
\hline 11 & $\begin{array}{l}\text { Would you accept robot as a hero/heroine in a movie of } \\
\text { your choice? }\end{array}$ & $33 \%$ & $67 \%$ & $\begin{array}{c}\text { Not } \\
\text { acceptable }\end{array}$ \\
\hline 14 & $\begin{array}{l}\text { Would you accept robot as prime minister/president of } \\
\text { your country? }\end{array}$ & $11 \%$ & $89 \%$ & $\begin{array}{c}\text { Never } \\
\text { acceptable }\end{array}$ \\
\hline 15 & $\begin{array}{c}\text { Would you hire a robot for a surgery of your family } \\
\text { member? }\end{array}$ & $36 \%$ & $64 \%$ & $\begin{array}{l}\text { Somehow } \\
\text { acceptable }\end{array}$ \\
\hline 16 & Would you accept a robot offering security? & $64 \%$ & $36 \%$ & $\begin{array}{c}\text { Highly } \\
\text { acceptable }\end{array}$ \\
\hline 17 & $\begin{array}{l}\text { Would you accept a robot offering police or fire } \\
\text { services? }\end{array}$ & $67 \%$ & $33 \%$ & $\begin{array}{c}\text { Highly } \\
\text { acceptable }\end{array}$ \\
\hline 18 & Would you accept robots serving as soldiers or military? & $69 \%$ & $31 \%$ & $\begin{array}{c}\text { Highly } \\
\text { acceptable }\end{array}$ \\
\hline 19 & $\begin{array}{l}\text { Would you accept a robot offering childcare/babysitting } \\
\text { services? }\end{array}$ & $33 \%$ & $67 \%$ & $\begin{array}{c}\text { Not } \\
\text { acceptable }\end{array}$ \\
\hline
\end{tabular}

To convert the quantitative data into qualitative data, the following table has been used to determine acceptability of these services:

Table 2: Acceptability Chart

\begin{tabular}{|c|c|}
\hline Above $60 \%$ & Highly acceptable \\
\hline $50-59 \%$ & Acceptable \\
\hline $35-49 \%$ & Acceptable \\
\hline $25-34 \%$ & Not acceptable \\
\hline Below 25\% & Never Acceptable \\
\hline
\end{tabular}


It can be interpreted from the above table that robots, which are considered to be the future of AI are acceptable in specific areas only, not all service fields.

a) The Indian society is ready to accept the services of robots as salespersons, maids, servants, massagers, receptionist, steward, waiters, air hostess, security in charge, police officers, firemen and soldiers etc. For one particular service waiter/waitress, the score was highest for it's acceptability by respondents.

b) The Indian society is not ready to accept robots beauticians, pilots, drivers, hero, heroines or baby sitters as robots.

c) Services like teacher and surgeons are not easily acceptable but can be accepted if need arises.

\section{- Views on use of artificial intelligence}

A general view on entry of robots was collected with respect to benefit to Indian working women, Indian domestic laborers and organizational environment. The data has been displayed in the following table:

Table 3: Impact of Artificial Intelligence

\begin{tabular}{|l|l|l|l|l|}
\hline S. No. & Questions on use of artificial intelligence & \multicolumn{1}{|c|}{$\begin{array}{c}\text { Affirmative } \\
\text { reply (Yes) }\end{array}$} & $\begin{array}{c}\text { Negative } \\
\text { Reply (No) }\end{array}$ & $\begin{array}{l}\text { Acceptability } \\
\text { of statement }\end{array}$ \\
\hline 1 & $\begin{array}{l}\text { Artificial intelligence will make the life of } \\
\text { working women easy. }\end{array}$ & 64 & $\begin{array}{l}\text { Highly } \\
\text { acceptable }\end{array}$ \\
\hline 2 & $\begin{array}{l}\text { Artificial intelligence will make the } \\
\text { organizations conflict free }\end{array}$ & $\begin{array}{l}\text { Somehow } \\
\text { acceptable }\end{array}$ \\
\hline 3 & $\begin{array}{l}\text { Artificial intelligence will help to ease the } \\
\text { domestic labor for Indians }\end{array}$ & 76 & $\begin{array}{l}\text { Highly } \\
\text { acceptable }\end{array}$ \\
\hline
\end{tabular}

The above data has been displayed in the image form below:

Diagram 16: Views on Impact of Artificial Intelligence

\section{Views on Impact of Artificial Intelligence}

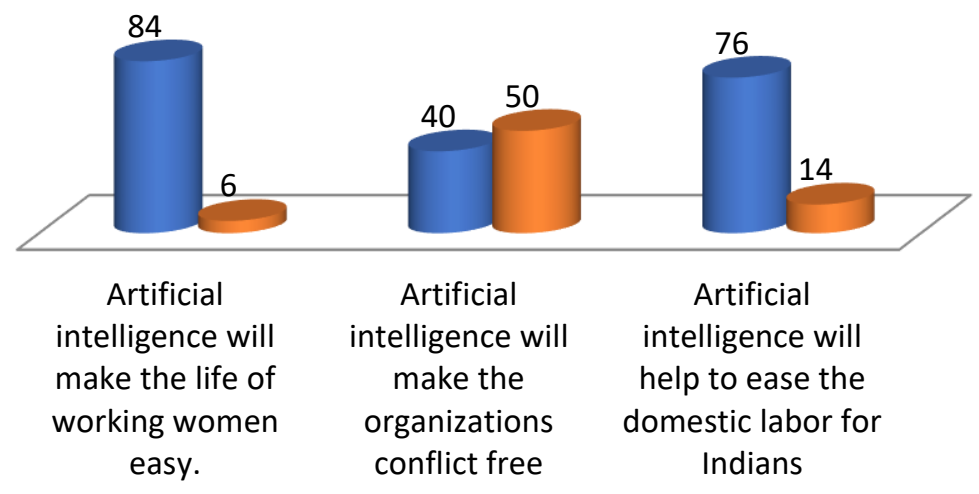


The assumption of acceptability has been used to assess the acceptability of statement. After applying the assumptions of acceptability, we see that an impact is foreseen in terms of less labour at the household front, but at the same time the respondents are doubtful if robots will be of any use to build a better work culture in the organizations.

- Status of Indian markets for (FMCG) after entry of robots: Data to study perception on the nature of market for fast moving consumer goods was collected and the following results were received:

Table 4: Status of Indian FMCG Market after entry of Robots

\begin{tabular}{|c|c|c|}
\hline S. No. & Status of market & $\begin{array}{c}\text { Number/percentage of } \\
\text { respondents }\end{array}$ \\
\hline 1 & Highly competitive & $38(42.2 \%)$ \\
\hline 2 & Oligopoly & $22(24.4 \%)$ \\
\hline 3 & Monopoly & $14(15.6 \%)$ \\
\hline 4 & No change from the present scenario & $16(17.8 \%)$ \\
\hline
\end{tabular}

Diagram 17: Status of Indian markets (For FMCG) after entry of robots

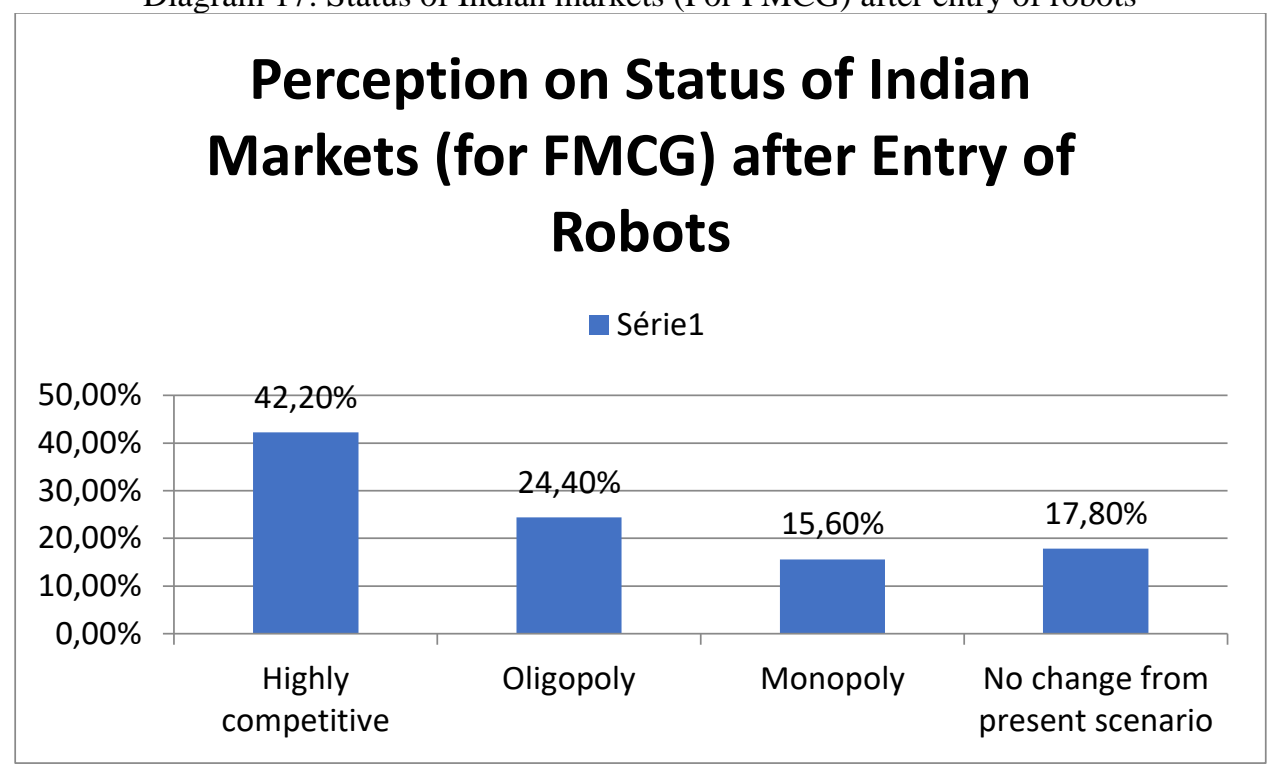

$42.2 \%$ perceive a very competitive future market after the entry of robots into economy, 24.4 percent see oligopoly in the changing environment, while 15.6 percent have a thought on monopolistic environment. $17.8 \%$ perceive that there will be no change from the present scenario.

- Contribution of robots in increasing GDP: Perception of respondents for contribution of robots in GDP growth of the country has been displayed in the diagram $19.42 \%$ respondents believe that robots will make positive contribution to GDP of the country, while $58 \%$ perceive that they will not contribute to the GDP. 
Diagram 18: Contribution of robots in Increasing GDP

\section{Large no. of robots in the country may help in increasing the GDP.}

Affirmative Answer (Yes) $\quad$ Negative Answer (No)

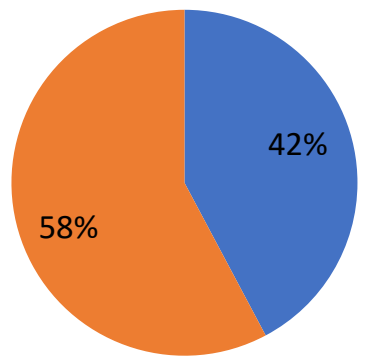

- Employment pattern of the country after the entry of robots :

a) When asked about the employment pattern of the country after entry of robots , $47 \%$ respondents are of the view that there will be no job for humans and 53\% said that only white collar jobs will be available for the humans. The following diagram displays the perception of the sample.

Diagram 19: Status of Jobs for Humans

\section{Status of Jobs for Humans}

No jobs for humans $\quad$ Only white collar jobs for humans

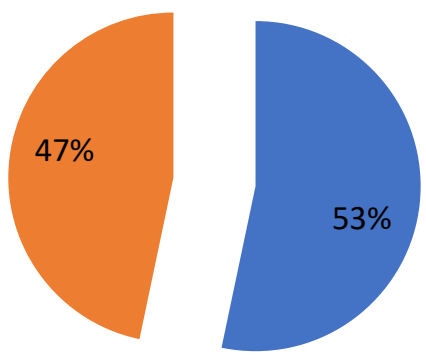

b) If robots start replacing employees in organizations, they will be taking over lower, middle or topmanagement?

In answer to this question, $51.1 \%$ respondents replied that the robots will capture lower level of 
Table 5: Perception on Status of Robot Employees

\begin{tabular}{|l|l|}
\hline Level of Management & No./Percentage of Respondents \\
\hline Lower level of management & $46(51.1 \%)$ \\
\hline Middle level of management & $38(42.2 \%)$ \\
\hline Higher level of management & $6(6.7 \%)$ \\
\hline
\end{tabular}

Diagram 20:Perception on Status of Robot Employees in Organizations

\section{Perception on Status of Robot Employees in Organizations of India}

- Lower level of management Middle level of management

Higher level of management

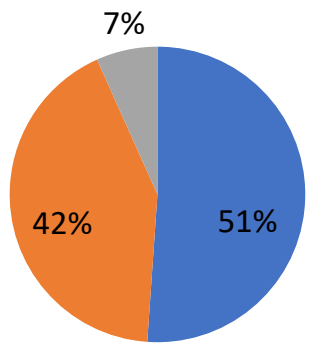

- Contribution of AI in global coverage for Indian products: 73\% respondents see an opportunity of With the help of artificial intelligence services, global market will be covered for Indian products while 27 do not see such an opportunity as shown in the diagram below:

Diagram 21:Global Market Coverage for Indian Products

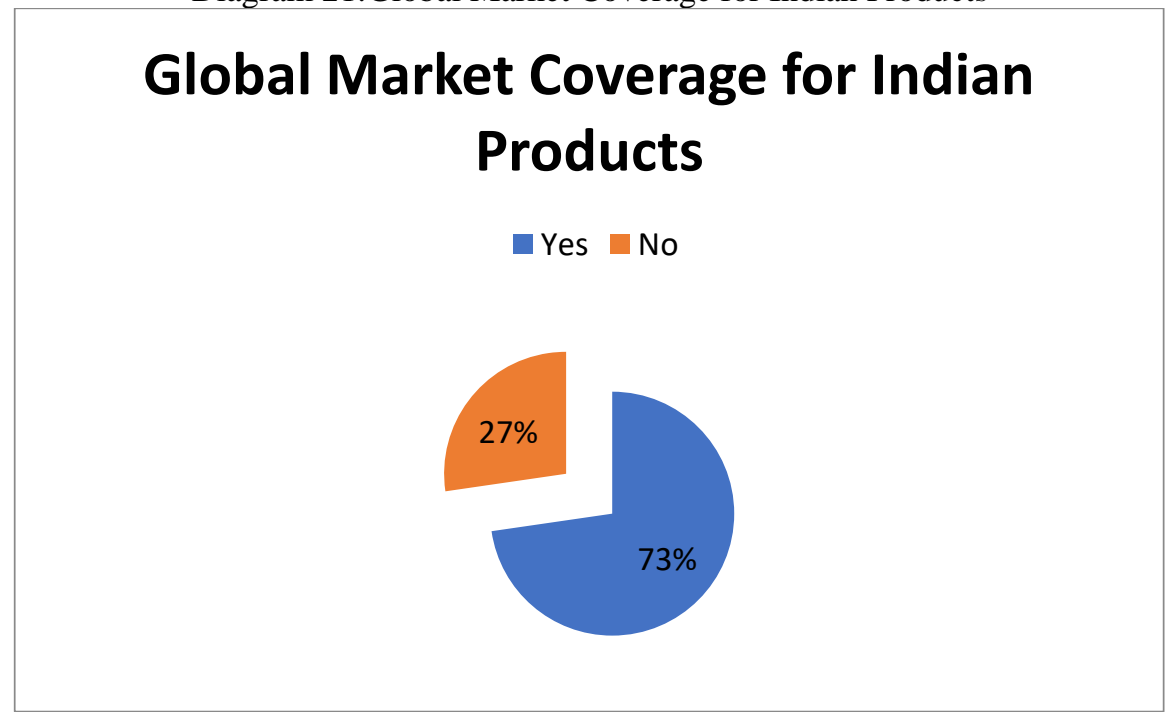


- Perception of Respondents on promoting AI for economic benefits: An open ended question was used to collect the data for this perception of the sample. Summarized answers of the respondents are given in the table below:

Table 6: Perception of Respondents on Promoting AI for Economic Benefits

\begin{tabular}{|c|c|}
\hline Answers received & Interpretation and analysis \\
\hline Should be promoted & Affirmative perception \\
\hline Reduces the cost (so should be promoted) & Affirmative perception \\
\hline $\begin{array}{c}\text { Can be helpful at times but can also have adverse effects } \\
\text { - } \quad \text { Can surpass humans } \\
\text { - } \\
\text { - } \\
\text { Conflicts will become more severe } \\
\text { More competitive markets }\end{array}$ & View of limited promotion of AI \\
\hline $\begin{array}{l}\text { Promoted to some extent but not in such a way that human existence } \\
\text { becomes null and void. } \\
\text { - It should reduce the stress, not replace them } \\
\text { - } \quad \text { Promotion of AI for economic benefits will reduce } \\
\text { working humans } \\
\text { - } \quad \text { This will affect human survival }\end{array}$ & View of limited promotion of AI \\
\hline Should be promoted to maintain quality and increase convenience. & Affirmative perception \\
\hline AI can drastically enrich and empower human life & Affirmative perception \\
\hline Needed for growth as saves time, energy and money & Affirmative perception \\
\hline Promoted for a boom to country's economic growth & Affirmative perception \\
\hline Should not be promoted as much bith is necessary & Should not be promoted \\
\hline Yes, it will help ease the difficulties & Affirmative perception \\
\hline Should be promoted & Affirmative perception \\
\hline We should use it for easier life & Affirmative perception \\
\hline $\mathrm{Ai}$ is not to be encouraged in all fields of life or day to day life & View of limited promotion of AI \\
\hline AI should be developed to make life easier & Affirmative perception \\
\hline $\begin{array}{l}\text { Should be promoted in the following areas only } \\
-\quad \text { Security } \\
-\quad \text { Medical } \\
\text { - } \quad \text { High risk tasks } \\
\text { To reduce failure and risk of life }\end{array}$ & View of limited promotion of AI \\
\hline Should be promoted for better output & Affirmative perception \\
\hline Will increase productivity & Affirmative perception \\
\hline $\begin{array}{l}\text { Should be promoted with intense care, it should not develop } \\
\text { intellectual mastery over humans }\end{array}$ & View of limited promotion of AI \\
\hline Should be promoted & Affirmative perception \\
\hline Should be promoted in defense and army systems & View of limited promotion of AI \\
\hline $\begin{array}{l}\text { AI is too advanced to precede human intelligence in near future. } \\
\text { Kill switch is suggested if it takes over the humanity in } 50 \\
\text { years.Balance mechanism is required for danger and gains both. }\end{array}$ & View of limited promotion of AI \\
\hline AI should be designed as per the need of economy & View of limited promotion of AI \\
\hline Yes, will cut down government expenditure & Affirmative perception \\
\hline Yes, should be promoted & Affirmative perception \\
\hline Yes, should be promoted & Affirmative perception \\
\hline Indifferent & No Views \\
\hline May be yes & Affirmative perception \\
\hline No comment & No views \\
\hline Yes, should be promoted for work efficiency & Affirmative perception \\
\hline Yes, should be promoted for better economical reach & Affirmative perception \\
\hline Yes, should be promoted but with limitation & View of limited promotion of AI \\
\hline No view & No view \\
\hline Should be promoted to some extent & View of limited promotion of AI \\
\hline Should not be promoted & Should not be promoted \\
\hline
\end{tabular}




\begin{tabular}{|l|l|}
\hline Yes, should be promoted & Affirmative perception \\
\hline Will give some benefits & Affirmative perception \\
\hline Yes, should be promoted & Affirmative perception \\
\hline Rural areas should be developed first before they start adapting AI & View of limited promotion of AI \\
\hline Yes, should be promoted for help in financial problems & Affirmative perception \\
\hline $\begin{array}{l}\text { If AI is promoted solely for economic benefits it would be } \\
\text { disastrous.AI should be promoted : }\end{array}$ & View of limited promotion of AI \\
$\quad-\quad$ For upgrading poor working conditions \\
This ensures less power of AI at top decision making
\end{tabular}

\section{ALL ABOVE REPLIES CAN BE DIVIDED INTO THE FOLLOWING THREE}

\section{CATEGORIES:}

1. Yes, should be promoted $-60 \%$

2. Should be promoted with certain limitations -32

3. Should not be promoted $-8 \%$

Diagram 21: Perception on Promotion of Artificial Intelligence

\section{Perception on Promotion of Artificial Intelligence}

Should be promoted $\quad$ Limited promotion No Views

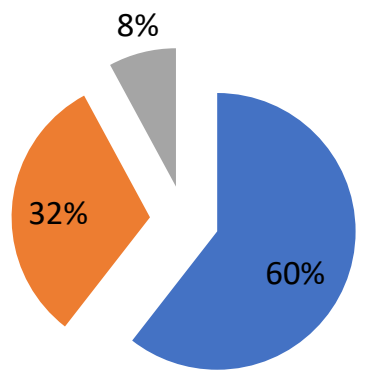

\section{FINDINGS}

- There are many fears associated with AI:
- AI can surpass humans
- Conflicts can be severe
○ More competitive markets
- Human existence may become null and void.
- AI may affect human survival.
- $\mathrm{AI}$ is too advanced to precede human intelligence.
○ Would be disastrous if aims at economic benefits only. 
- AI services are used recurrently for buying medicine, in travel directions, in being entertained, news and information search and collection, entertaining senior citizens, taking financial/legal advice in cooking meals and in teaching. This help may be in the form of taking recipes, collecting notes, selecting movies/shows, using maps or any other type of activity that helps in the main activity.

- If robots replace humans in certain job profiles, they will be accepted at the designation of salesperson, maid, servant, massagers, receptionist/steward, waiter/waitress, security officers, or soldiers. But there are certain areas where robots are not acceptable at all, like beauticians, pilots, drivers, heroes/heroines and babysitters.

- The robots can never replace administrative head of a country, people do not have a mindset of accepting robots to dictate them.

- People think that robots are not in a position to surpass the human brains/muscles atleast for next twenty years.

- People tend to think that Ai will ease the domestic labor for men and women both in the country.

- AI may not prove helpful in resolving conflicts inside the organizations.

- Indian markets are foreseen as highly competitive or oligopolistic.

- Robots are not accepted at the highest level of management in organizations. They can be accepted at middle and lower level of management only.

- If robots enter the organizations, there will be only white collar jobs for humans, though the fear of no jobs at all also accompanies the perception.

- People expect robots to contribute in GDP of the country if they are allowed to take over business activities.

\section{CONCLUSION}

A blend of varying perceptions from the users of $\mathrm{AI}$ in this research can be noticed. In some areas AI and robots are highly accepted and appreciated as they reduce the human labor in routine or technical activities. At the same time acceptability is little difficult in the relatively sensitive areas. Economic benefits are being realized only from technical areas as of now, The opportunities in the sensitive services are not being explored and utilized by AI service providers.

\section{SUGGESTIONS AND RECOMMENDATIONS}

- Till the time robots are not accepted in all the fields, they should be used only in specific technical areas like security and defense or at the reception or in technical service like legal or financial advices etc. 
- Highly sensitive areas like babysitting, beauty care, acting, driving. etc. should not be given in the hands of robots till the consumers are not comfortable in using the services given by them.

- There is more need of building trust amongst the consumer population to make the robots acceptable for sensitive services like teaching and healthcare which can impact the existence, survival and growth of mankind.

- Light jobs like posting on to the social media sites regularly is the favorite most area of consumers' choice.

- The fear shown by respondents needs to be handled carefully for economic benefits, once rejected by consumers the business opportunity in $\mathrm{AI}$ is lost for Organizations.

- AI can prove useful in performing mechanics like fixing machines, but is less popular amongst the users, so the industry players should focus on the promotion of the service.

- A genuine check on over development of AI is always to be checked and kept under control either by legal or technical control measures.

- People are still looking at AI as a labor reducing instrument only. Awareness should be spread for more possible benefits.

\section{IMPLICATIONS}

If the study achieves the target of economic analysis of artificial intelligence and human beings relationship and succeeds in developing a theoretical model for economic benefits from artificial intelligence then this will contribute towards an uplift in the social as well as economic environment of the country. For the purpose of analysis statistical tools like T test, Z test mayl be used for better research outcome.

Further scope of the study can be checking the acceptance of robots as per the psychology of the consumers when it comes to variety of services. For example a robot may be accepted as a doctor, but would you recommend a robot for a surgery of one of your family members. Or when you have choice between a robot doctor and a human doctor, who will be chosen? Many such questions still remain unanswered and can be the scope of further researches.

\section{LIMITATIONS}

The study involves a small sample size of 90, the findings are limited to the sample studied and cannot be generalized for the huge population. 


\section{REFERENCES}

1. https://ai.google/about/ retrieved on $10^{\text {th }}$ July, 2019.

2. Allan M. Jordan, ACS Medicinal Chemistry Letters. 'Artificial Intelligence in Drug Design - The Storm Before the Calm' 2018, 9, 12, 1150-1152

3. Ajay Agarwal, Joshua Gans and Avi Goldfarb, Advances in Artificial Intelligence' University of Chicago Press, 2019.

4. Bostrom, N., \&Yudkowsky, E. (2014). The Ethics of Artificial Intelligence. In K. Frankish \& W Ramsey(Eds) The Cambridge Handbook of Artificial Intelligence (pp. 316-334). Cambridge University Press.

5. Bolton, Charlynne,VeronikaMachová, Maria Kovacova, and Katarina Valaskova (2018). “The Power of Human-Machine Collaboration: Artificial Intelligence, Business Automation, and the Smart Economy,” Economics, Management, and Financial Markets 13(4): 51-56.

6. Bryn Jolfsson, Eric e Mcafee, Andrew (2016), The Second Machine Age, Norton Paperback, New York.

7. Goyal Jayanti (October 11-142017) Artificial Intelligence: A New Tool for Managing Stress' BICON-2017, Work Stress and Health: Leading Innovations and Strategies towards Stress management, Biyani Group of Colleges, Jaipur.

8. Jerry Kaplan (2016) 'Artificial Intelligence: What Everybody Wants to Know' Oxford University Press, New York.

9. J. Mark Munoz and Al Naqvi, 'Business Strategy in the Artificial Intelligence Economy', Business Expert Press, 2018.

10. Luke Dormehl,( 2017)‘'Thinking Machines’ Tarcher Perigee Book, New York.

11. Boden, M.A.(1998). 'Creativity and Artificial Intelligence' Artificial Intelligence, 103 (1-2), 347356.

12. Ford Martin (2016) 'Rise of the Robots: Technology and the Threat of Jobless Future', Basic Books, New York.

13. https://blogs.wsj.com/cio/2018/11/16/the-impact-of-artificial-intelligence-on-the-worldeconomy/, retrieved on $9^{\text {th }}$ July, 2019.

14. Huang M.H., \& Rust R. T. (2018). 'Artificial Intelligence in Service' Journal of Service Research , 21 (2), 155-172.

15. Amar Raju G., Souvikroy, Santanu Mandal, (December, 2018) 'Determinants of Website Usability: Empirical Evidence from Tourism Sector in India' Global Business Review, SAGE Publications, 19 (6), pp1640-1662. 
16. Tiruveedula Gopi Krishna, Mohammed A. Abdelhadi, Madusudana Subramanyam (December, 2013)'Expert System in Real World Business', International Journal of Advance Research in Computer Science and Management Studies, 1 (7)

17. Yunhe Pan(2016) 'Heading Toward Artificial Intelligence 2.0' Engineering 2 (2016), 409-413. 